\title{
Estado Nacional e desenvolvimento: construindo um sistema financeiro a serviço do projeto de desenvolvimento nacional
}

\author{
Matheus Felipe de Castro ${ }^{1}$
}

\begin{abstract}
Sumário: Introdução; 1. Capacidade financeira do Estado brasileiro; 2. Principais pontos de uma reforma tributário/financeira funcionalmente predisposta à realização do projeto político de desenvolvimento nacional; Conclusão; Referências.
\end{abstract}

Resumo: O presente artigo avalia a capacidade financeira do Estado brasileiro, como nação dependente e subdesenvolvida e propõe medidas de política econômica destinadas a subordinar os sistemas tributário e financeiro à realização de um projeto político de desenvolvimento nacional, fundado no pleno emprego e na justiça social, cujas linhas gerais estão traçadas na própria Constituição da República Federativa do Brasil, de 1988.

Palavras-chave: estado; constituição, desenvolvimento; sistema tributário e financeiro.

\begin{abstract}
This article assesses the financial capacity of the Brazilian State, as a dependent and underdeveloped nation, and proposes measures for economic policy to make tax and financial systems to achieve a political project of national development, based on full employment and social justice, whose main lines are drawn in Brazil's Constitution.
\end{abstract}

Keywords: state; constitution; development; tax and financial system.

\section{Introdução}

A Constituição da República Federativa do Brasil, de 1988, traçou as linhas gerais de um avançado projeto político de desenvolvimento nacional a partir da compreensão de que a trajetória histórica da nação brasileira e de seu povo acumulou problemas relacionais e estruturais que precisam ser superados pelo desenvolvimento da própria democracia. Objetivou, com isso, construir um regime orientado para a consolidação de uma sociedade de bem-estar, fundada no pleno emprego e na justiça social, desempenhando papel na construção de um moderno sistema produtivo que garanta o desenvolvimento do mercado interno com agregação de

1 O autor é advogado e doutor em Direito, Estado e Constituição pela UFSC. 
produção tecnológica avançada, eliminação de graves vulnerabilidades externas (subdesenvolvimento/ dependência) e de crônicas disparidades internas (pobreza, marginalidade, exclusão social), inclusão de grandes parcelas subempregadas no sistema formal de trabalho com todos os seus benefícios (trabalhistas e previdenciários), fortalecimento dos laços de coesão social, construindo uma sociedade política e economicamente soberana e desenvolvida. Ou seja, um sistema econômico funcionalizado (politicamente dirigido) pela própria função social da propriedade privada, da empresa e do contrato, que permita o grande salto de uma democracia formal para uma democracia material ou econômica.

Entretanto, um dos principais gargalos que o Estado brasileiro enfrenta para se reconstituir em Estado desenvolvimentista (political developer), retomando as rédeas do desenvolvimento perdidas desde a década de 1980, é a sua capacidade financeira lato sensu, ou seja, sua capacidade de se financiar e de constituir um aparelho eficiente de financiamento do desenvolvimento nacional com base nos objetivos sociais constitucionalmente traçados. Numa nação marcada pela escassez de receita tributária, o Estado teve que se financiar junto ao capital financeiro nacional e internacional reiteradas vezes, potencializando a dependência e a manutenção do subdesenvolvimento. Os organismos financeiros internacionais impuseram reformas estruturais em contrapartida aos empréstimos, liberalizando o aparelho de Estado e desmontando importantes instrumentos de intervenção no domínio econômico.

O presente artigo tem por finalidade abordar essa relação estreita entre desenvolvimento e capacidade financeira do Estado, relação que se expressou de forma tensa na última década como uma pretensa (e, evidentemente, inexistente) contraposição entre Constituição econômica e financeira da República Federativa do Brasil, com vistas à retomada do desenvolvimento nacional. Apresenta, enfim, propostas concretas para a refuncionalização do aparelho de Estado, para a sua reorganização financeira e tributária.

\section{Capacidade financeira do Estado brasileiro}

O advento da constituição dirigente no Brasil impôs ao Estado, agora economicamente intervencionista e socialmente redistribuidor, 
a realização de fins predispostos pela comunidade política, em contraposição ao antigo Estado de tipo liberal-abstencionista, que se limitava a estruturar e formatar o aparelho de Estado, seus órgãos específicos e suas competências, delegando à iniciativa privada e à livre concorrência a direção do desenvolvimento. A constatação da existência de uma ordem social injusta e desigual e de uma ordem econômica subdesenvolvida e dependente - destituída de dinamismo próprio que garantisse a acumulação interna de excedentes - e a predisposição de que o Estado efetivasse ações direcionadas à superação dessa realidade caracterizou o novo quadro que marcaria a própria consolidação do Modo Capitalista de Produção a partir da Revolução de 1930.

Desde a Constituição de 1934, as novas funções que o Estado nacional chamou para si nos terrenos social e econômico colocaram a necessidade da ampliação de sua capacidade financeira funcionalmente predisposta. O nacional-desenvolvimentismo inaugurou uma era de grande desenvolvimento industrial capitalista, a partir da indução política do Estado, contando, para tanto, com o contingenciamento de verbas públicas na efetivação de obras de infraestrutura e na promoção da indústria de base. Evidentemente, a receita tributária sempre teve papel proeminente no financiamento das atividades estatais, mas historicamente acabou se mostrando insuficiente em nações de capitalismo periférico.

A economia brasileira surgiu a partir dos processos de colonização que marcaram a expansão da economia mercantil a partir de um centro inicialmente localizado na Europa Ocidental. Dessa forma, o seu desenvolvimento se operou em estreita dependência para com os capitais externos. O Estado nacional brasileiro nasceu endividado, uma vez que assumiu, no processo da Independência, boa parte da dívida externa portuguesa junto à Inglaterra, contraindo empréstimo de dois milhões de libras esterlinas, em $1825,{ }^{2}$ como condição ao reconhecimento português da Independência.

Portanto, se nas nações de capitalismo central o desenvolvimento econômico foi impulsionado pela abundância de capitais, em nações localizadas na periferia do capitalismo, como o Brasil, o desenvolvimento econômico foi marcado pela escassez de capitais nacionais, em virtude do

2 JOFFILY, Bernardo. Istoé Brasil 500 anos: atlas histórico. São Paulo: Três S/A, 1998, p. 46. 
esquema colonial que impôs formas crônicas de desacumulação na periferia com correlata acumulação em prol das nações mais desenvolvidas.

O paradigma que marca, portanto, o desenvolvimento financeiro do Estado brasileiro foi o da escassez de receita tributária (derivada da escassez de excedentes econômicos locais), em virtude da acumulação precária derivada de uma economia periférica, especializada na produção de produtos primários para abastecimento das nações industriais da Europa e América do Norte, geradoras de mais-valor.

A depreciação dos termos de troca entre nações produtoras de bens primários e nações produtoras de bens com grande valor agregado (nações industriais, tecnologicamente inovadoras), determinou uma tendência histórica ao achatamento da acumulação interna das primeiras e, consequentemente, das fontes de financiamento tributário do Estado.

Essa escassez de receita tributária levou o Estado brasileiro, por um lado, a uma constante dependência de empréstimos externos, ora realizados perante governos, ora realizados perante o sistema financeiro internacional, que acabou por determinar grande vulnerabilidade do Estado diante de outras nações, aquilo que Celso Furtado designou por internacionalização dos centros da decisão econômica nacional e, por outro, a consolidação de um sistema tributário altamente regressivo, em que os setores mais débeis da cadeia econômica arcaram com a maior fatia do financiamento público.

A questão da acumulação de excedentes internos mostrou-se, assim, a pedra de toque da questão financeira do Estado. Um círculo vicioso onde a economia nacional não se desenvolveu ao ponto de gerar excedentes suficientes que pudessem ser reinvestidos na ampliação do parque produtivo, com geração de emprego e renda para amplas camadas da população, com o Estado, em consequência, não conseguindo arrecadar receita tributária suficiente para investir na reprodução, seja do fator trabalho - mediante a garantia de salário indireto, via implementação de programas sociais - seja do fator capital produtivo - mediante o investimento em obras públicas e indução política do desenvolvimento de atividades geradoras de mais-valor - em áreas consideradas estratégicas para o desenvolvimento nacional.

O período histórico do nacional-desenvolvimentismo foi marcado por diferentes concepções a respeito do financiamento do Estado (interno 
ou externo), mas na prática prevaleceu a ampla participação do capital estrangeiro na receita pública. Mesmo na era Vargas, marcada pelo nacionalismo e pela desconfiança em relação ao capital internacional, não se prescindiu dessa forma de financiamento do Estado. No período Kubitschek, o Estado brasileiro lançou mão amplamente dos capitais estrangeiros para o financiamento do Estado e da iniciativa privada, o que se transformou em verdadeira política de Estado na ditadura militar de 1964-1985.

A crise do nacional-desenvolvimentismo, internamente, e a crise da dívida, externamente, contribuíram para que o Estado brasileiro adentrasse a década de 1980 em grave colapso financeiro, que praticamente imobilizou seus instrumentos de intervenção no domínio econômico e redistribuição no domínio social. A anterior abundância de recursos, derivada dos empréstimos externos a juros negativos, foi revertida com as decisões do FED - Federal Reserve, de aumentar a taxa de juros estadunidense, o que inverteu o fluxo de capitais das nações periféricas para os EUA.

A década de 1980, pós-Milagre, ficaria conhecida como década perdida, e, depois dela, o advento do neoliberalismo subverteria a própria concepção financeira do Estado, ao inserir um novo paradigma financeiro fundado não na reprodução dos fatores trabalho e capital produtivo (D-M-D'), mas na reprodução do capital financeiro e especulativo, representado no circuito condensado D-D'. A dominância do capital portador de juros teria grande impacto sobre as funções do Estado social traçado pela Constituição - a reprodução da "forma valor" financeirizada pulveriza os fundamentos de um Estado social, na medida em que os fatores capital produtivo e trabalho assalariado, que se encontram na base daquela construção política, são relativizados, enquanto produtores da riqueza nacional - e a crise financeira acima exposta imobilizaria o Estado em suas funções econômicas e sociais, tornando-o refém de medidas liberalizantes que o tornariam, em certa medida, um instrumento de redistribuição às avessas, pela remuneração preferencial do capital.

Mas antes do advento do neoliberalismo no país, a Constituição da República Federativa do Brasil de 1988 reafirmaria o papel dirigente do Estado, vinculando a sua capacidade financeira à realização dos fins que a comunidade política lhe definiu. A Constituição Cidadã estabeleceria um profundo e inovador programa de ações sociais e econômicas, 
determinando ao Estado a realização de um conjunto de atividades dirigidas à erradicação da pobreza e da marginalização, com redução das desigualdades sociais e regionais, bem como de atividades dirigidas ao fim de desenvolver o parque produtivo brasileiro, valorizando o mercado interno e colaborando para a superação do subdesenvolvimento e da histórica dependência brasileira. Nela, na Carta de 1988, pode-se observar a firme determinação político-jurídica de intervir ativamente em uma Ordem Econômica marcada por graves assimetrias sociais e regionais. Celso Furtado asseverava que:

O ponto de partida do estudo do desenvolvimento deveria ser não a taxa de investimento, ou a relação produto-capital, ou a dimensão do mercado, mas sim o horizonte de aspirações da coletividade em questão, considerada esta não abstratamente, mas como um conjunto de grupos ou estratos com perfil definido, assim como o sistema de decisões que prevalece nessa sociedade e os fatores limitantes que escapam ao poder interno de decisão. O desenvolvimento é a transformação do conjunto das estruturas de uma sociedade em função de objetivos que se propõe alcançar essa sociedade. O primeiro problema é definir o campo de opções que se abre à coletividade. Em seguida se apresenta o problema de identificar entre essas opções aquelas que se apresentam como possibilidade política, isto é, que, correspondendo a aspirações da coletividade, podem ser levadas à prática por forças políticas capazes de exercer um papel hegemônico no sistema de poder. ${ }^{3}$

Aqui se encontra, portanto, a segunda pedra de toque do tema sobre a capacidade financeira do Estado. Parodiando Celso Furtado, o ponto de partida do estudo da capacidade financeira do Estado, deve ser, não as taxas de arrecadação, a confecção das peças orçamentárias, a relação tributária em si ou as dimensões dos mercados tributados, mas sim o horizonte de aspirações da coletividade em questão, definidos politicamente em sua constituição total e que se cristalizam no projeto político de desenvolvimento nacional.

O advento do Estado social e da constituição dirigente no Brasil teve o condão de diagnosticar uma realidade social prenhe de disparidades

FURTADO, Celso. A hegemonia dos Estados Unidos e o subdesenvolvimento da América Latina. 2. ed. Rio de Janeiro: Civilização Brasileira, 1975, p. 131. 
sociais, econômicas e políticas e predispor fins, ou seja, definir metas de superação dessa realidade, mediante ações concretas a partir do terreno do político, da intervenção ativa e consciente do homem, coletivamente considerado, na história.

Dessarte, a constituição financeira do Estado, aqui considerada o conjunto de instrumentos jurídicos e institucionais (administrativos) criados e mantidos com a finalidade de garantir a sua capacidade financeira, deve estar submetida à realização daquele horizonte de aspirações da coletividade que foram cristalizados na constituição social, aqui considerada como os fins que a comunidade política predispôs para a construção de uma democracia econômica, com erradicação da pobreza e da marginalidade e redução das desigualdades sociais e regionais, e na constituição econômica, aqui considerada como os fins que a comunidade política predispôs para construir uma nação economicamente soberana, independente e desenvolvida.

Quando se identifica, com clareza, a constituição socioeconômica, como o conjunto de fins que o Estado deve alcançar, ou seja, como a sua própria razão de existência, delimita-se o quadro político-institucional onde deve ser desenvolvida a constituição financeira do aparelho de poder concentrado e organizado de uma sociedade determinada. E a Constituição da República Federativa do Brasil, de 1988, definiu esses fins com clareza: a) construir uma sociedade livre, justa e solidária, erradicando a pobreza e a marginalização e reduzindo as desigualdades sociais e regionais; b) garantir o desenvolvimento nacional. A própria Carta definiu que a forma de se alcançar esses objetivos seria através da construção de uma sociedade de bem-estar, com pleno emprego dos fatores de produção, ou seja, do trabalho e do capital produtivo.

Com isso se quer dizer, resumidamente, que a Constituição da República Federativa do Brasil de 1988 definiu como fim primeiro do Estado brasileiro, a administração das condições gerais à reprodução equilibrada da forma valor, representada no circuito produtivo D-M-D' funcionalizado, isto é, a reprodução do modo capitalista de produção submetido à realização dos fins sociais, políticos e econômicos definidos pela comunidade política reunida em assembleia nacional constituinte.

É esse o marco político-institucional que deve determinar a construção e reprodução da constituição financeira do Estado: o aparelho 
financeiro deve estar predisposto a reproduzir o circuito produtivo D-M-D' funcionalizado, o que significa, em termos miúdos, que o aparelho financeiro do Estado deve ser um instrumento de efetivação dos programas definidos nas constituições econômica e social que compõem a constituição total, segundo um planejamento racional de transformação das estruturas social, econômica e política de uma formação social concreta.

Dessa forma, retira-se a discussão financeira e orçamentária do terreno meramente técnico-jurídico, ressaltando seus marcados aspectos políticos definidos pela Constituição de 1988. Régis Fernandes de Oliveira destaca o aspecto político do orçamento ao afirmar que ele "é um plano de ação exposto à consideração pública. Ele reflete a estratégia política do governo, as suas metas, prioridades, política social e econômica". ${ }^{4}$ Realmente, através das previsões orçamentárias, pode-se identificar a visão ideológica de um determinado governo.

$\mathrm{O}$ sistema financeiro estatal que surge com o neoliberalismo e as reformas institucionais que lhe foram correlatas pressupôs, exatamente, desvincular a constituição financeira das constituições econômica e social, no interior da constituição total, como bem ressaltaram Bercovici e Massonetto, ${ }^{5}$ diminuindo o papel teleológico daquelas e o papel instrumental da primeira.

Como fica evidente, esse procedimento separador ocorreu em função do retorno às velhas concepções de um Estado de molde liberalabstencionista, que, em não devendo se enveredar numa seara que seria de monopólio da sociedade civil e do mercado, deveria se contentar em manter uma estrutura mínima (com tripartição de poderes, divisão de competências e manutenção de uma força pública) e só. Os autores ressaltam que:

O problema deste processo de reestruturação das finanças públicas e da estrutura financeira do Estado brasileiro foi o fato de que a recomposição da capacidade de intervenção pública se esgotou

4 OLIVEIRA, Régis Fernandes de. Curso de direito financeiro. São Paulo: Revista dos Tribunais, 2006, p. 322.

5 BERCOVICI, Gilberto; MASSONETTO, Luís Fernando. A constituição dirigente invertida: a blindagem da constituição financeira e a agonia da constituição econômica. Boletim de Ciências Econômicas, Coimbra, XLIX, 2006, separata, p. 3. 
na tentativa de controle sobre os gastos públicos. A constituição financeira de 1988, que deveria dar suporte para a implementação da constituição econômica de 1988, falhou nesta tarefa. Um dos motivos é a separação que a doutrina e a prática constitucionais pós1988 promoveram entre a constituição financeira e a constituição econômica, como se uma não tivesse nenhuma relação com a outra e como se ambas não fizessem parte da mesma Constituição de 1988. A constituição financeira passou a ser interpretada e aplicada como se fosse "neutra", meramente processual, com diretrizes e lógica próprias, separada totalmente da ordem econômica e social, esterilizando, assim, a capacidade de intervenção do Estado na economia. Separada da constituição financeira, a constituição econômica de 1988 foi transformada em mera "norma programática". ${ }^{6}$

Assim, diminuídas as funções teleológicas da constituição social e econômica, abriu-se espaço para o desenvolvimento de uma ordem financeira não mais compromissada com a reprodução dos fatores trabalho e capital produtivo, ou seja, da forma valor representada no circuito clássico D-M-D' (funcionalizado pela Constituição de 1988), e o que se viu foi a estruturação de um sistema financeiro estatal preocupado com a reprodução do capital financeiro, representado no circuito fetichista D-D', o que pode ser facilmente percebido quando se analisa a transmudação das finalidades dos fundos públicos e do orçamento da União no período do advento do neoliberalismo.

Os fundos públicos e o orçamento geral, desde o advento do Estado intervencionista no Brasil, estiveram vinculados àquela reprodução, já mencionada, do fator trabalho, através da promoção de salários indiretos, fornecidos através da implementação de serviços públicos e direitos sociais, como saúde, educação, transporte coletivo, saneamento básico, cultura, aperfeiçoamento profissional, lazer, etc., e do fator capital produtivo, na medida em que o Estado intervinha no terreno econômico, induzindo e incentivando o desenvolvimento do setor produtivo principalmente o substitutivo de importações - e implementando, ele mesmo, empresas estatais (empresas públicas e sociedades de economia mista), encarregadas de desenvolver atividades econômicas que, pela sua natureza, demandariam altos investimentos por parte da iniciativa privada, com retorno de alto risco ou de longo prazo.

6 BERCOVICI; MASSONETTO, 2006, p. 12-13. 
Com o advento do neoliberalismo, os fundos públicos mudam de função, não mais servido para, por meio de direitos sociais e serviços públicos, assegurar a reprodução da força de trabalho e por meio de investimentos e obras públicas reproduzir o capital produtivo, passando também a ser disputados com o objetivo de garantir a própria remuneração do capital financeiro. ${ }^{7}$

Explica-se: para os economistas keynesianos, o déficit público seria necessário para garantir o pleno emprego, forma de garantir o desenvolvimento das forças produtivas e a dinâmica inovadora do Modo Capitalista de Produção regulado, eis que o mercado real (não o teórico dos neoclássicos) não seria suficiente nos tempos atuais (se é que um dia o foi), para, por si só, fomentar um desenvolvimento soberano, eis que a crença num mercado auto-regulável, capaz de se autodinamizar já havia sido abandonada, desde a década de 1930, com as grandes crises econômicas que abateram o centro do capitalismo mundial.

Entretanto, com o neoliberalismo, a lógica de um déficit público garantidor do pleno emprego dinamizador do desenvolvimento foi abandonada em prol de outra lógica, para a qual os fundos e o orçamento do Estado devem estar direcionados à remuneração direta do capital portador de juros, o que se realizou, no Brasil, através de uma série de medidas implementadas principalmente com a Lei de Responsabilidade Fiscal - proibindo o déficit público na implementação das medidas e ações previstas nas constituições econômica e social, com o fim de garantir que a União, os Estados e os Municípios fossem dotados de solvabilidade diante do capital portador de juros invertido em Títulos da Dívida Pública - e a instituição do superávit primário, espécie de fundo público destinado a garantir o pagamento dos juros da dívida pública. Explicam Bercovici e Massonetto:

Esta crise de financiamento do setor público é ainda mais grave nos países periféricos, como o Brasil, em que há insuficiência de recursos para o financiamento público da acumulação de capital. Portanto, para garantir a atração dos investimentos privados, o Poder Público brasileiro tem que estabilizar o valor real dos ativos das classes proprietárias. Ou seja, o orçamento público deve estar voltado para a garantia do investimento privado, para a garantia

BERCOVICI; MASSONETTO, 2006, p. 14. 
do capital privado, em detrimento dos direitos sociais e serviços públicos voltados para a população mais desfavorecida. Assim, nesta etapa, o direito financeiro, na organização do espaço políticoeconômico da acumulação, passa a servir a uma nova função do Estado - a tutela jurídica da renda do capital e da sanção de ganhos financeiros privados, a partir da alocação de garantias estatais ao processo sistêmico de acumulação liderado pelo capital financeiro. ${ }^{8}$

Com o neoliberalismo, o Estado brasileiro, que vinha se financiando de forma precária com base na receita tributária e em empréstimos contraídos junto ao capital financeiro internacional, passou a inverter sua dívida externa em dívida interna, através da securitização de títulos de sua dívida pública - como o fez os EUA e outras nações que aderiram à economia financeirizada - criando mecanismos de garantia desses títulos, como o superávit primário e a imposição de uma taxa básica de juros definida por um Banco Central independente na prática do poder político e dos representantes eleitos democraticamente pelo povo.

A estabilidade da moeda - pressuposto para a criação de um ambiente de relativa segurança jurídica, política e econômica para a proliferação do capital portador de juros - tornou-se um dogma, suplantando o desenvolvimento como meta constitucionalmente traçada pela comunidade política nacional, o que fica evidente quando o governo brasileiro traça metas inflacionárias anuais, deixando de estabelecer metas de crescimento econômico.

A deliberação sobre o orçamento público tornou-se uma questão meramente técnica, subtraída aos debates democráticos, perdendo o seu conteúdo político instrumental de garantidor da implementação das políticas sociais e econômicas previstas na Constituição de 1988. A implementação da ordem econômica e da ordem social, previstas na Constituição Cidadã, ficaram restritas às sobras orçamentárias e financeiras do Estado brasileiro. ${ }^{9}$ A Lei no 10.028, de 19 de outubro de 2000, criminalizou o déficit público, proibindo assim a realização do pleno emprego, revogando, na prática, o princípio constitucional do pleno emprego, previsto no artigo 170, VIII, da Constituição de 1988, que permaneceu como um mero "discurso programático", ou seja, uma carta e boas intenções.

8 BERCOVICI; MASSONETTO, 2006, p. 15.

9 BERCOVICI; MASSONETTO, 2006, p. 17 
Pois bem. A constituição financeira do Estado, o seu aparelho financeiro, o seu direito financeiro, os fundos públicos (principalmente a previdência social), a receita tributária, o orçamento público devem ser redimencionados a partir das imposições concretas determinadas originariamente pela Constituição de 1988. A política monetária sempre foi um instrumento a serviço da política econômica e da política social, até que, como ressaltou Leda Paulani, transformou-se na determinante primeira e tirânica de toda a estruturação macroeconômica, o que representou, na prática, a renúncia decisiva do poder, que o Estado teoricamente detém, de fazer política econômica. ${ }^{10}$

Com isso se quer dizer que não há tributo, que não há orçamento público, que não há medida financeira que não deva passar pelo paradigma que localiza esses mecanismos como instrumentos de efetivação das medidas previstas nas constituições econômica e social, ou seja, no projeto político de desenvolvimento nacional, que tem, por fim último, construir uma nação desenvolvida e soberana, que promova a eliminação da marginalidade e a diminuição das disparidades sociais e regionais.

O planejamento é o meio adequado para agregar ou sistematizar os instrumentos financeiros do Estado de acordo com as funções que a Constituição de 1988 garantiu aos seus cidadãos. Uma reforma do sistema de arrecadação (o sistema tributário nacional) de recursos de financiamento estatal deve ter como compromisso: a) o fomento à alocação de recursos na reprodução da forma valor, vale dizer, na reprodução dos fatores trabalho e capital produtivo (D-M-D'), principalmente do setor de inovação tecnológica, o que se opera através da isenção ou subtaxação da produção, circulação e consumo de bens duráveis ou não e de serviços; b) a repressão à alocação de recursos na reprodução da forma valor financeirizada (D-D'), o que se opera através da supertaxação da atividade especulativa, do capital portador de juros e do patrimônio particular (ou seja, a acumulação pessoal, não empresarial, ou, dito de outra forma, a acumulação estática em contraposição à dinâmica que se evidencia na empresa, gerando valor); c) a estruturação de um sistema amplamente fundado nos princípios da progressividade e da capacidade contributiva,

${ }_{10}$ PAULANI, Leda. Alternativas para o Brasil no início do século XXI. In: SICSÚ, João (Org.). Arrecadação (de onde vem?) e gastos públicos (para onde vão?). São Paulo: Boitempo, 2007, p. 79-80. 
fazendo com que a carga tributária recaia sobre as parcelas sociais mais abastadas; d) a vinculação direta dos recursos arrecadados à realização das medidas previstas na constituição econômica (desenvolvimento nacional, desenvolvimento tecnológico, afirmação das empresas nacionais, redução das disparidades regionais, consolidação do mercado interno como patrimônio nacional, etc.) e social (saúde, educação, esporte, lazer, previdência e assistência sociais, etc.), estruturando um sistema tributário/ financeiro redistribuidor de riquezas, na forma de salários indiretos.

Os desafios do desenvolvimento no Brasil recolocam a necessidade de o Estado Nacional se reafirmar como Estado financeiro, articulando em torno de si um poderoso sistema bancário estatal encarregado de disponibilizar o crédito para o financiamento da forma valor produtiva [D-M-D'] e do pleno emprego, com vistas à construção de uma sociedade de bem-estar e justiça social. Os bancos para isso já existem (Caixa Econômica Federal e Banco do Brasil) e só precisam ser articulados dentro de um grande projeto político de desenvolvimento nacional, com o BNDES liderando o processo de direcionamento do crédito para atividades consideradas estratégicas para a consolidação do mercado interno nacional, como o desenvolvimento tecnológico e infraestrutura.

Quando se fala em sistema financeiro, fala-se de um sistema de intermediações no qual quem detém poupança disponibiliza-a, mediante pagamento de juros, para quem não a tem e deseja investir num ramo produtivo ou não. Hoje a poupança dos nacionais encontra-se concentrada nas mãos de bancos privados, fundos de pensão e fundos de investimento, com alto grau de instabilidade, visto que suas aplicações preferenciais encontram-se nos setores especulativos da economia, sujeitos a crises, a processos de deságio de capitais fictícios, afora as possibilidades de quebra e fraudes praticadas por seus gestores.

Nesse sentido, o Estado precisa criar formas de canalizar a poupança nacional para setores produtivos da economia, geradores de bases reais para o desenvolvimento, o que pode ser realizado através da transformação do capital portador de juros politicamente controlado, num instrumento de redistribuição social da riqueza gerada pela economia nacional, ${ }^{11} \mathrm{o}$

11 Assim como o mercado, o capital portador de juros não é "bom" ou "mal" por natureza. Deixado por si só, tende a gerar o rentismo, a especulação e a concentração de renda sem causa. Mas uma vez politicamente controlado pelo Estado e colocado a serviço do 
que já pode ser realizado através do direcionamento dos excedentes que compõem os fundos sociais (FAT, FGTS, PIS, PASEP, Fundo Soberano) para as atividades produtivas que interessam ao desenvolvimento nacional, com remuneração do capital mediante juros reincorporados aos fundos e/ou desenvolvimento do aparelho previdenciário/assistencial do Estado, como, por exemplo, com a criação de nova fonte de custeio da previdência social ou de serviços públicos essenciais.

Com isso, o Estado "funcionaliza" o próprio capital portador de juros, colocando-o a serviço da realização do projeto político de desenvolvimento nacional ao submetê-lo àquilo que deveria ser a sua função clássica: uma forma de aceleração e consolidação do circuito produtivo D-M-D', composto por capital e trabalho. Não se trata, portanto, de hostilizar o capital portador de juros, mas de submetê-lo aos interesses definidos pela comunidade política nacional.

O fundo da questão é que, na atual quadra histórica do Modo Capitalista de Produção, o crédito se consolidou como o elemento central do funcionamento do sistema. Se o Estado não detém um mínimo controle sobre o sistema de crédito, a iniciativa privada o instrumentaliza para atividades de maior lucratividade imediata (atividades especulativas no circuito D-D'), que não interessam para o desenvolvimento de uma economia sólida nos marcos do Estado nacional, gerando, a médio e longo prazo, prejuízos evidentes para o conjunto da comunidade nacional.

Se o sistema creditício é submetido à Constituição, torna-se ele mesmo um instrumento de efetivação das metas por ela projetada, com grande potencial de transformação das relações sociais postas, eliminandose disparidades internas e vulnerabilidades externas que impedem o Brasil de se consolidar como nação soberana, desenvolvida e independente. Se o Estado abre mão, em prol da iniciativa privada, do controle sobre o crédito, abre-se enorme brecha por onde se consolida a soberania de mercado em face da soberania popular.

desenvolvimento e da construção de uma sociedade fundada na justiça social, pode se tornar um instrumento de governo importante para a realização de fins éticos definidos constitucionalmente. Nesse sentido, o capital portador de juros deve ser funcionalizado, ou seja, deve ele também cumprir uma função social, na medida em que representa uma forma de propriedade do capital. 


\section{Principais pontos de uma reforma tributário/financeira funcionalmente predisposta à realização do projeto político de desenvolvimento nacional}

O presente trabalho não se insere nas raias de uma Teoria Geral do Estado, ${ }^{12}$ mas sim numa teorização sobre um Estado concreto, fruto das contradições de uma formação social concreta. Trata-se da análise e síntese do aparelho de poder concentrado e organizado de uma sociedade concreta, fruto de um desenvolvimento histórico particular.

Destarte, na análise do sistema tributário/financeiro de um Estado concreto, há que se verificar de que Estado se está falando. Já se verificou que o Estado brasileiro, definido pela Constituição dirigente de 1988, é um Estado economicamente intervencionista e socialmente redistribuidor, com nítidos e explícitos compromissos constitucionais com a construção de uma sociedade de bem-estar e pleno emprego, desenvolvimento tecnológico e superação de disparidades sociais e regionais internas, bem como de vulnerabilidades externas que impedem o desenvolvimento dos potenciais sociais, políticos e econômicos da nação perante a comunidade internacional.

Não se adotou um modelo liberal-abstencionista de Estado. Portanto, se a tributação tem a finalidade de arrecadar recursos para o financiamento das atividades estatais, ela também tem a finalidade de regular as atividades econômicas (papel de intervenção no domínio econômico) e redistribuir renda e riqueza entre os diversos setores sociais e as diversas regiões nacionais, marcadas por extremas disparidades. Dessa maneira, a formatação técnica de um sistema financeiro/tributário de uma nação vincula-se aos marcos político-institucionais constitucionalmente definidos e que expressam fins e funções que devem ser exercidas pelo Estado, vale dizer, ao papel que a comunidade política, diante de uma correlação de forças determinada, definiu como uma meta a ser efetivada.

\footnotetext{
12 O "Estado", como entidade abstrata, não existe na história. O que existem são Estados concretos desenvolvendo-se no tempo. A presente tese se propôs não à análise de princípios que se revelassem aplicáveis a todos os Estados, em geral, mas a análise da lógica ou dinâmica particular de um Estado concreto: a República Federativa do Brasil, em sua fase mais desenvolvida.
} 
Dessa forma, um sistema financeiro/tributário impõe algumas questões: 1) que tipo de Estado está definido pela Constituição? Um Estado liberal-abstencionista ou um Estado intervencionista-social?; 2) Quais as funções definidas a esse Estado pela sua constituição, ou, dito de outra forma, quais os objetivos a ser alcançados pelo Estado? 3) Qual o volume de recursos necessários à realização daqueles fins? 4) Quem ou que classes, categorias ou segmentos sociais arcarão com o maior peso da carga tributária, o que significa perguntar, quem arcará com o financiamento do Estado? 5) Que tipos de atividades estatais os grupos sociais estão dispostos a arcar (ou não arcar) com uma maior carga tributária?

Como se pode observar, todas elas são perguntas de natureza política e nascem da correlação das forças sociais presentes numa formação social determinada, e por isso mesmo não são estáticas, mas dinâmicas, marcadas por avanços e reveses para ambos os lados. O DIEESE - Departamento Intersindical de Estatística e Estudos Socioeconômicos sintetizou, em nota técnica, a resposta às perguntas elencadas acima:

O primeiro objetivo de um sistema tributário deve ser promover o desenvolvimento socioeconômico, isto é, induzir o crescimento econômico, de forma sustentável, com geração de empregos, melhor distribuição de renda, justiça social e eliminação da pobreza. Em função da acentuada concentração de renda e riqueza, o sistema tributário brasileiro, ainda mais do que em outros países, deve ser instrumento privilegiado de redistribuição de renda e recursos e desconcentração da posse da riqueza, priorizando o recolhimento de tributos dos "mais ricos" e os gastos em políticas e regiões que vão beneficiar os "mais pobres". ${ }^{13}$

Entretanto, o sistema tributário/financeiro brasileiro vigente de fato, desde o advento do neoliberalismo, está fundado numa matriz teórica de corte liberal, fundamentada no pensamento dos economistas clássicos e neoclássicos. Para os economistas neoclássicos a economia seria marcada por uma situação de equilíbrio estável e igualdade formal entre os agentes econômicos, qualificada por relações concorrenciais, pleno emprego

13 DIEESE. Em que sentido o sistema tributário brasileiro deve ser reformulado? In: Nota Técnica 68. Disponível em: <http://www.dieese.org.br>. Acesso em: 25 jul. 2008. 
dos fatores de produção e dinâmica automática de desenvolvimento dos mercados, de maneira que o Estado se configuraria numa entidade estranha ao processo de desenvolvimento econômico.

Destarte, estaria vetado ao sistema tributário nacional romper o equilíbrio dos mercados, afetando as decisões dos agentes econômicos na alocação dos recursos sociais, como também estaria vetada a utilização do sistema tributário com o fim de alterar a estrutura "natural" da distribuição da renda entre os diversos setores sociais. ${ }^{14}$

Esse sistema vigente de fato não corresponde à ideologia constitucionalmente adotada pela Constituição da República Federativa do Brasil de 1988, que se definiu como carta econômica e social, e por isso mesmo, dirigente. Não é demais lembrar que a Constituição, em seu artigo 3o, previu dois objetivos ao Estado brasileiro que devem estar no vértice da constituição do sistema tributário e do sistema financeiro público no Brasil: a) a garantia do desenvolvimento nacional; e b) a erradicação da pobreza e da marginalização, bem como das desigualdades sociais e regionais.

Somente a citação desses dois objetivos já seria suficiente para fixar os marcos ideológicos do Estado brasileiro, como um Estado de bem-estar social, economicamente intervencionista - devendo predispor todos os meios a seu alcance para, através da intervenção consciente na realidade social, induzir o desenvolvimento econômico, social e político da nação - e socialmente redistribuidor - devendo predispor instrumentos para igualizar os desiguais sociais e regionais.

Mas a Constituição de 1988 foi além, e no seu artigo 170, previu que o Estado brasileiro deveria garantir a justiça social, através da garantia política do pleno emprego (inciso VIII), constituindo-se em empregador de última instância, o que pressupõe a realização de déficits públicos de pleno emprego; no seu artigo 145, § 1ํㅡㅇ o princípio da capacidade contributiva, ${ }^{15}$ pelo qual os contribuintes deverão ser tributados conforme

14 SALVADOR, Evilásio. A distribuição da carga tributária: quem paga a conta? In: SICSÚ, João (Org.) Arrecadação (de onde vem?) e gastos públicos (para onde vão?). São Paulo: Boitempo, 2007, p. 79-80.

15 CARRAZZA, Roque Antônio. Curso de direito constitucional tributário. 11. ed. São Paulo: Malheiros, 1998, p. 65: "Realmente, é justo e jurídico que quem, em termos 
sua capacidade econômica; no seu artigo 149, a previsão de instituição de contribuiçõos sociais de intervenção no domínio econômico; e no seu artigo 153, inciso III e $\S 2^{\circ}$, inciso I, o critério da progressividade, pelo qual os tributos devem ser estruturados de forma em que suas alíquotas variem para mais à medida em que forem aumentando suas bases de cálculo, ${ }^{16}$ vale dizer, tributando mais aqueles que detêm mais poder econômico.

Como se vê, o regime tributário e financeiro atualmente vigente no Brasil não corresponde à Constituição total vigente porque há um típico conflito ideológico-constitucional entre o que é e o que deveria ser. De um lado, vige uma Constituição de nítido corte intervencionista/ social que predispõe seus instrumentos políticos com o fim de equilibrar situações que se encontram em desequilíbrio e, de outro, a contrastar, um típico sistema tributário de natureza liberal-abstencionista, no qual o Estado deve, pelo contrário, garantir a permanência do establishment mediante a instituição de um sistema tributário fundado na igualdade formal ${ }^{17}$ de todos perante a lei ou até mesmo regressivo, em que quem tem menos poder econômico acaba por arcar com a maior fatia da carga tributária.

A correlação de forças entre as classes, frações de classe e grupos sociais é determinante para se compreender sobre quem recai, preponderantemente, a carga tributária nacional (e mesmo a sua composição), ou seja, as despesas do Estado. ${ }^{18}$ Fabrício Augusto de Oliveira ressalta que:

econômicos, tem muito, pague, proporcionalmente, mais impostos do que quem tem pouco. Quem tem maior riqueza deve, em termos proporcionais, pagar mais imposto do que quem tem menor riqueza. Noutras palavras, deve contribuir mais para a manutenção da coisa pública".

16 CARRAZZA, 1998, p. 65.

17 Quando a Constituição de 1988 previu, em seu artigo 150, inciso II, que seria vedado à União, aos Estados e aos Municípios “instituir tratamento desigual entre contribuintes que se encontrem em situação equivalente”, por evidente não consagrou um princípio liberal da isonomia formal, mas o princípio da igualização material dos desiguais. Dessa forma, a lei tributária deve tratar igualmente os contribuintes de idêntica capacidade contributiva e desigualmente os contribuintes de diferentes capacidades contributivas, efetivando o princípio da progressividade e da contribuição conforme à capacidade econômica do contribuinte.

18 SALVADOR, 2007, p. 82. 
[...] a correlação das forças políticas e sociais atuantes no sistema encontra-se na base da determinação da distribuição dos impostos diretos e indiretos, ou seja, na composição da carga tributária. Caso essa correlação seja desfavorável aos trabalhadores, por exemplo, tenderão a predominar, na estrutura tributária, os impostos indiretos, que são caracteristicamente regressivos e instrumentos que contribuem para piorar a distribuição de renda, com baixas incidências sobre a renda, os lucros e o patrimônio. Caso a luta política se revele favorável para a atenuação das desigualdades sociais, certamente os impostos diretos adquirirão maior importância, como comprova a experiência dos países desenvolvidos. ${ }^{19}$

O sistema tributário vigente privilegia a arrecadação fundada nos tributos indiretos (passíveis de ser transferidos para terceiros), que recaem sobre a produção, a circulação, o consumo de bens e serviços e o trabalho, independentemente da capacidade econômica de quem se tributa, enquanto um sistema tributário progressivo deveria se fundar, preponderantemente nos tributos diretos (impassíveis de ser transferidos para terceiros), que recaem sobre a renda e a propriedade ou patrimônio.

No primeiro caso, a carga tributária recai com mais intensidade sobre os fatores trabalho e capital produtivo, vale dizer, sobre o circuito D-M-D' (dinâmico, gerador de riqueza social), enquanto no segundo caso, a carga tributária recai com mais intensidade no capital portador de juros representado no circuito D-D' e nas grandes fortunas e propriedades, vistas essas em seu caráter estático ou meramente parasitário. ${ }^{20}$

19 OLIVEIRA, Fabrício Augusto de. Economia e política das finanças públicas: uma abordagem crítica da teórica convencional, à luz da economia brasileira. Texto referência da disciplina Finanças Públicas, do Mestrado em Administração Pública da Fundação João Pinheiro, Belo Horizonte, 2001, p. 108.

${ }^{20}$ SALVADOR, 2007, p. 82 chama a atenção para o caráter absolutamente regressivo dos tributos indiretos, onde o consumidor é quem acaba por arcar com o peso da carga tributária: "Trata-se do fetiche do imposto: o empresário nutre a ilusão de que recai sobre seus ombros o ônus do tributo, mas sabe-se que esse valor integra a estrutura de custos da empresa, sendo, em geral, repassado aos preços. Os tributos indiretos são regressivos". 
Estimativa da carga tributária brasileira, por base de incidência 2005

\begin{tabular}{l|r|r|r}
\hline Tributos por base de incidência & R\$/Milhões & \% do PIB & $\begin{array}{l}\text { Participação } \\
\text { percentual }\end{array}$ \\
\hline Consumo & $\mathbf{4 0 2 . 7 9 4}$ & $\mathbf{1 8 , 8}$ & $\mathbf{5 8 , 7}$ \\
\hline Imposto sobre Importação & 9.086 & 0,4 & 1,3 \\
\hline $\begin{array}{l}\text { Imposto sobre Produtos } \\
\text { Industrializados }\end{array}$ & 26.373 & 1,2 & 3,8 \\
\hline COFINS & 87.902 & 4,1 & 12,8 \\
\hline Contribuição PIS/PASEP & 22.046 & 1,0 & 3,2 \\
\hline Cide-combustíveis & 7.680 & 0,4 & 1,1 \\
\hline CPMF & 29.230 & 1,4 & 4,3 \\
\hline $\begin{array}{l}\text { Imposto sobre Operações } \\
\text { Financeiras }\end{array}$ & 6.102 & 0,3 & 0,9 \\
\hline $\begin{array}{l}\text { Contribuição previdenciária das } \\
\text { empresas }\end{array}$ & 48.050 & 2,2 & 7,0 \\
\hline ICMS & 154.810 & 7,2 & 22,6 \\
\hline ISS & 11.515 & 0,5 & 1,7 \\
\hline Renda & $\mathbf{1 7 3 . 1 2 2}$ & $\mathbf{8 , 1}$ & $\mathbf{2 5 , 2}$ \\
\hline Imposto de Renda do trabalho & 43.162 & 2,0 & 6,3 \\
\hline $\begin{array}{l}\text { Contribuição previdenciária dos } \\
\text { trabalhadores }\end{array}$ & 22.182 & 1,0 & 3,2 \\
\hline Imposto de Renda do capital & 51.130 & 2,4 & 7,5 \\
\hline $\begin{array}{l}\text { Contribuição Social sobre Lucro } \\
\text { Líquido }\end{array}$ & 26.322 & 1,2 & 3,8 \\
\hline Outras rendas & 30.326 & 1,4 & 4,4 \\
\hline Patrimônio & $\mathbf{2 3 . 6 0 6}$ & $\mathbf{1 , 1}$ & $\mathbf{3 , 4}$ \\
\hline Imposto Territorial Rural & 324 & 0,0 & 0,0 \\
\hline IPVA & 10.497 & 0,5 & 1,5 \\
\hline ITCD & 79.804 & 0,0 & 0,1 \\
\hline IPTU & 2.186 & 0,1 & 0,3 \\
\hline ITBI & $\mathbf{8 6 . 3 3 4}$ & $\mathbf{4 , 0}$ & $\mathbf{1 2 , 6}$ \\
\hline Totras tributos & $\mathbf{3 1 0 5 6}$ & $\mathbf{3 1 , 9}$ & $\mathbf{1 0 0 , 0 0}$ \\
\hline
\end{tabular}

Fonte: Salvador (2007), com base na SRF, STN, Confaz

Obs.: 1) Não inclui depósito de FGTS, por ser considerado "salário diferido".

2) Dados dos municípios com base na variação nominal da arrecadação tributária das capitais

3) Os dados da carga em relação ao PIB apresentados por Salvador (2007) foram atualizados de acordo com os valores recalculados do PIB divulgados pelo IBGE em 2007. 
A tabela acima transcrita evidencia que os tributos indiretos representaram, no ano-paradigma, 58,7\% do total arrecadado na União, nos Estados e nos Municípios, vistos em conjunto, enquanto o imposto sobre a renda pessoa física e jurídica alcançou apenas $25,2 \%$ do total arrecadado, e os tipos de tributos sobre a propriedade ou patrimônio, somente $3,4 \%$.

Essa opção política pelos tributos indiretos, que oneram o capital produtivo e o trabalho - a lógica valor funcionalizada D-M-D' constituem uma afronta ao projeto político de desenvolvimento nacional traçado na Constituição, na medida em que colaboram para a alocação de recursos nos setores especulativos marcados pela lógica D-D', imposta às nações periféricas pelo centro do capitalismo, ao mesmo tempo em que desconstroem o aparelho social do Estado, forçando para que os fundos públicos de investimento social sejam revertidos para o pagamento dos juros da dívida pública. A natureza intervencionista do Estado é diminuída na mesma medida em que é diminuída a sua natureza redistributiva.

Dessarte, o sistema tributário nacional vigente estabeleceu uma forma de redistribuição às avessas, onde a arrecadação recai preponderantemente sobre os trabalhadores, com grave carga regressiva, sendo que a receita não é destinada à implementação dos salários indiretos consubstanciados nas medidas sociais e econômicas previstas na Constituição, mas à formação de gigantescos superávits fiscais, destinados ao pagamento dos juros sobre a dívida pública aos rentistas proprietários de Títulos do Tesouro Nacional. ${ }^{21}$

O Banco Central do Brasil, através do Comitê de Política Monetária, estabelece a taxa básica de juros (Selic), que nada mais é que o índice de remuneração do capital portador de juros invertido nos Títulos da Dívida Pública. Aliás, na variação da taxa Selic é que se pode observar, com clareza, a correlação de forças entre o capital financeiro, de um lado, e

21 POCHMANN, Márcio. Gasto social, o nível de emprego e a desigualdade da renda do trabalho no Brasil. In: SICSÚ, João (Org.). Arrecadação (de onde vem?) e gastos públicos (para onde vão?). São Paulo: Boitempo, 2007, p. 77, lembra que: "Enquanto programas como o Bolsa Família garante a 8 milhões de famílias o acesso a um benefício monetário, cujo montante representa somente $0,3 \%$ do PIB, a política de juros do Governo Federal transfere anualmente a poucas famílias ricas uma quantia monetária equivalente a $7 \%$ do PIB. Por conta disso, torna-se muito difícil conter a desigualdade de renda e riqueza no Brasil". 
o capital produtivo e o trabalho, de outro, no seio do governo central do Estado brasileiro, o que evidencia a natureza contraditória e correlacional do exercício do poder, numa estrutura que internalizou a luta de classes, mediante adoção de critérios político-jurídicos de igualdade formal.

Destarte, torna-se imprescindível uma reforma que constitucionalize os sistemas tributário, financeiro, orçamentário e monetário nacional (momentos de uma mesma totalidade integrada), adequando-os à ideologia constitucionalmente adotada pela Carta de 1988, que é uma carta dirigente, com nítidos compromissos econômicos e sociais.

Os sistemas tributário e financeiro devem ser, como já mencionado, instrumentos estatais destinados a: a) induzir o desenvolvimento nacional (artigo 3ㅜㅡ, inciso II), o que pressupõe incentivar a reprodução da forma valor (D-M-D') produtiva e reprimir a reprodução da forma valor financeirizada (D-D'), ou funcionalizá-la; b) servir de instrumento de redistribuição social, colaborando para a erradicação da pobreza e da marginalidade e redução das desigualdades sociais e regionais.

Essa vinculação estreita e política (não técnica) entre arrecadação (sistema tributário), administração financeira, orçamentária e monetária, com a constituição econômica e social, é o fio condutor que permite reconduzir a administração financeira de Estado aos trilhos assentados pela comunidade política nacional em sua constituição. Destarte, as medidas de reforma passam por:

1) Exercer o controle da remessa de lucros e/ou capitais valorizados no Brasil ao exterior. A legislação brasileira privilegia a evasão de divisas, sendo paradigmática dessa questão a Lei nº 9.249/95, que estabelece isenção do imposto de renda sobre as remessas de lucros ao exterior, ao mesmo tempo em que a legislação impõe elevadas alíquotas para o reinvestimento interno desses mesmos capitais no setor produtivo. $\mathrm{O}$ investimento externo direto não deve ser hostilizado, mas sim direcionado aos setores industriais de interesse estratégico para o desenvolvimento nacional, criando-se mecanismos de incentivo da permanência desses valores no território nacional.

2) Controle sobre o fluxo internacional de capitais voláteis, devendo-se estabelecer pesados custos monetários sobre os capitais de curto prazo, de natureza especulativa. A taxa Tobin, 
idealizada pelo economista estadunidense James Tobin, da Universidade de Yale e laureado com o Nobel de Economia em 1981, pode ser o início do desenvolvimento de uma forma eficaz para controlar a expansão do capital portador de juros e forçar o retorno do capital aos circuitos produtivos, embora não pareça ser suficiente, por si só, para realizar tal tarefa.

3) Redução da taxa de juros da dívida pública. Desde o advento da hegemonia neoliberal, o Banco Central brasileiro passou a funcionar numa espécie de autonomia de fato. Essa independência, que não é meramente organizativa, mas política, permitiu que setores representativos do capital financeiro se entrincheirassem em seus conselhos e comitês, principalmente no COPOM - Comitê de Política Monetária, de onde comandam, através da fixação da taxa Selic, os destinos da política monetária brasileira. O governo central encontrase destituído de poder de fato sobre essa estrutura. A política de viés monetarista, fundada nas metas inflacionárias que conferem segurança jurídica ao capital financeiro, impedem o desenvolvimento de políticas de desenvolvimento mais duradouras.

4) Diminuição do superávit primário e destinação dele ao investimento em infraestrutura econômica e social. $\mathrm{O}$ fundo público do superávit primário nada mais é que a poupança que o governo realiza para o pagamento e segurança ao capital portador de juros, invertido em Títulos da Dívida Pública. Isso significa que os fundos estatais estão sendo utilizados para reproduzir o circuito D-D', ou seja, o capital financeiro e não para reproduzir o capital produtivo e o trabalho representados em D-M-D'. Isso, como se viu, é absolutamente contrário à ideologia constitucionalmente adotada. A utilização dos fundos públicos para o pagamento de juros da dívida pública em detrimento da implementação das medidas econômicas e sociais previstas na Carta de 1988 é inconstitucional.

5) Restabelecimento da política do déficit público de pleno emprego. Há muito se superou a visão de que os mercados se desenvolvem de forma autônoma, dinamizados por um automatismo que faz lembrar as leis do reino animal. $\mathrm{Na}$ 
verdade, o mercado é uma instituição criada e mantida pelo Estado e por ele regulado. Sem a regulação estatal, o mercado ou os mercados não têm condições de se constituírem em promotores do desenvolvimento, ainda mais em nações de capitalismo periférico, onde as pressões advindas do centro do capitalismo mundial criam tendências desindustrializantes e especializadoras das economias periféricas em setores atrasados, primário-exportadores. Cabe ao Estado e somente a ele a realização de políticas de compensação, necessárias e suficientes para suprir as deficiências do mercado interno, consolidando-o como verdadeiro patrimônio nacional, como previsto no artigo 219 da Constituição de 1988. Para tanto, a política de pleno emprego é uma das formas reconhecidas e mais eficientes de se induzir a industrialização de uma nação no rumo do desenvolvimento tecnológico e de inovação.

6) Implementação de imposto de renda e imposto sobre o patrimônio fortemente progressivos. Como já ressaltado, os impostos diretos, de caráter progressivo, que tributam mais aqueles que mais possuem capacidade contributiva é uma importante medida de justiça fiscal, que recupera o caráter redistribuidor do Estado. O princípio da igualdade formal, aqui, encontra desdobramento quando se implementam medidas de igualização formal dos desiguais, o que está plenamente de acordo com um Estado de tipo intervencionista e social.

7) Fim da isenção do IR dos juros sobre capital próprio e sobre a remessa de lucros para o exterior. Como já mencionado, a Lei no 9.249/95 estabeleceu isenção do imposto de renda sobre a remessa de lucros ao exterior. Mas não só: permitiu a dedução de juros cobrados sobre o capital próprio das empresas, do lucro tributável ao Imposto de Renda e da CSLL - contribuição social sobre o lucro líquido. A Lei no 9.249/95, em seu artigo 9o, permite às pessoas jurídicas tributadas pelo lucro real que remuneraram pessoas físicas ou jurídicas a título de juros sobre o capital próprio considerarem tais valores como despesas para fins de apuração do Imposto de Renda Pessoa Jurídica (IRPJ) e da Contribuição Social sobre o Lucro Líquido (CSLL). Isso representa uma gigantesca renúncia fiscal do Estado brasileiro. 
8) A Isenção de imposto de renda sobre a distribuição de lucros e dividendos, estabelecida pelo artigo 10 da Lei na 9.249/95, privilegia a retirada do capital-dinheiro do circuito produtivo, migrando para o patrimônio pessoal, de natureza especulativa ou rentista. Representa gigantesca renúncia fiscal do Estado brasileiro frente ao rentismo, além de induzir a reprodução do capital portador de juros.

9) Constitucionalizar as políticas fisscal, financeira e orçamentária da União, tornando-as instrumentos efetivos da realização dos objetivos que a Constituição de 1988 determinou ao Estado brasileiro, ou seja, o desenvolvimento nacional (com fundamento nos seus mercados internos e na expansão do setor de inovação tecnológica), o pleno emprego e a eliminação da pobreza e da marginalidade e redução das desigualdades sociais e regionais, implementando um regime de verdadeira democracia econômica.

10) Priorizar a tributação direta e não cumulativa. Para favorecer a observância dos princípios da capacidade contributiva, pessoalidade e progressividade (IR, IPTU, IPVA, entre outros). Os tributos indiretos (IPI, ICMS, ISS) possuem forte carga regressiva, sendo arcados pelos consumidores finais, sendo que os mais pobres arcam com as mesmas cargas de tributos que os membros das classes mais abastadas. Ademais, a cumulatividade ou "efeito em cascata" de tributos acaba por onerar sobremaneira certos produtos para o consumo final. $\mathrm{O}$ imposto sobre valor agregado, proposto por Celso Furtado, ${ }^{22}$ elimina o perigo da cumulatividade, eis que tributa somente o valor agregado em cada etapa da cadeia de produção, desonerando o consumidor final.

11) Seletividade de bens e pessoas que devem e que não devem ser tributadas. Pessoas com maior capacidade contributiva devem ser tributadas enquanto pessoas com baixa capacidade econômica deveriam ficar isentas, realizando o princípio da igualização dos desiguais. Da mesma forma, produtos

${ }^{22}$ FURTADO, Celso. Considerações sobre o caso brasileiro. In: FURTADO, Celso. $A$ hegemonia dos Estados Unidos e o subdesenvolvimento da América Latina. 2. ed. Rio de Janeiro: Civilização Brasileira, 1975, p. 157. 
de primeira necessidade, como alimentos, vestuário e medicamentos, deveriam ser isentos de tributação. Por outro lado, os setores industriais de tecnologia de ponta e as indústrias de capital nacional deveriam receber tratamento tributário mais brando, visto que interessam para o desenvolvimento nacional e a consolidação do mercado interno.

12) A simplificação e objetividade do sistema tributário, além de conferir segurança jurídica, dificultaria as fraudes, elisões e evasões fiscais. A segurança jurídica é importante conquista do Estado democrático de direito, derivada do princípio da legalidade. Entretanto, não é um valor em si mesma. O capital financeiro goza de segurança jurídica na medida em que o Estado brasileiro garante seus lucros e ganhos. Segurança jurídica pressupõe estabilidade, mas estabilidade é algo difícil de ser alcançado numa sociedade de classes, onde a correlação de forças sociais é determinante dos rumos nacionais. Assim, a depender da correlação de forças, sempre algum grupo social se sentirá mais ou menos inseguro. Um sistema tributário e financeiro constitucionalizado é capaz de conferir maior segurança jurídica a todo o povo brasileiro, eis que a constituição é (ou deveria ser) a lei de maior estabilidade política na nação.

\section{Conclusão}

A superação da crise financeira que o Estado brasileiro vivencia desde o início da década de 1980 e que paralisou sua capacidade de intervenção no terreno econômico e social e a constitucionalização do sistema tributário, do sistema financeiro estatal, do orçamento público e da política monetária, com vistas a torná-los instrumentos verdadeiros, eficientes e interligados ou concatenados de realização da constituição econômica e social de 1988, constituem dos principais nós que precisam ser desatados para a construção de uma nação plenamente desenvolvida, com superação integral das graves disparidades internas e das crônicas vulnerabilidades externas que assolam a nação brasileira.

A forma preferencial de financiamento do Estado mediante venda, no mercado, de títulos da dívida pública, remunerando-se os 
capitalistas financeiros mediante as mais altas taxas oficiais de juros do mundo, coloca o Estado Nacional refém, em última instância, das determinações de mercado, que se guiam pela lógica microeconômica da maximização dos lucros/minimização dos custos. Em longo prazo, essa forma de capitalização se mostrou desastrosa no Brasil, tendo sido, de alguma forma, uma das grandes responsáveis pelo grande processo de desnacionalização ocorrido na década de 1990.

A contradição reside exatamente no fato de a Constituição de 1988 ter traçado a consolidação de um forte mercado interno, fundado em sólidas bases produtivas de riqueza, com valorização da livre iniciativa e geração de emprego e renda, e os fatos históricos terem levado o Estado brasileiro a se capitalizar junto ao mercado financeiro, cuja lógica estrita acaba por frear exatamente os mecanismos necessários à consolidação daquele projeto, visto que prescinde da sua passagem concreta pelos fatores capital e trabalho.

Somente com um poderoso sistema financeiro constitucionalmente funcional o Estado brasileiro poderá voltar a politizar a economia e a nacionalizar a política, como queria Celso Furtado quando reclamava a emergencial internalização dos centros de decisão econômica, pressuposto da construção de uma nação política e economicamente soberana. Sem essa internalização, a esfera do poder, determinante das escolhas e opções do desenvolvimento, restam alienadas a centros de decisão exterior - que se guiam pela lógica da acumulação no centro/desacumulação na periferia - ou a centros de decisão econômica - que se guiam pela lógica particular da maximização dos lucros individuais, em detrimento daquele horizonte de aspirações que deve guiar a trajetória de uma nação e de seu povo.

\section{Referências}

BERCOVICI, Gilberto; MASSONETTO, Luís Fernando. A constituição dirigente invertida: a blindagem da constituição financeira e a agonia da constituição econômica. Boletim de Ciências Econômicas, Coimbra, XLIX, 2006, separata.

CARRAZZA, Roque Antônio. Curso de direito constitucional tributário. 11. ed. São Paulo: Malheiros, 1998. 
DIEESE. Em que sentido o sistema tributário brasileiro deve ser reformulado? In: Nota Técnica 68. Disponível em: <http://www.dieese. org.br>. Acesso em: 25 jul. 2008.

FURTADO, Celso. A hegemonia dos Estados Unidos e o subdesenvolvimento da América Latina. 2. ed. Rio de Janeiro: Civilização Brasileira, 1975.

FURTADO, Celso. Considerações sobre o caso brasileiro. In: FURTADO, Celso. A hegemonia dos Estados Unidos e o subdesenvolvimento da América Latina. 2. ed. Rio de Janeiro: Civilização Brasileira, 1975. Quarta parte.

JOFFILY, Bernardo. Istoé Brasil 500 anos: atlas histórico. São Paulo: Três S/A, 1998.

OLIVEIRA, Fabrício Augusto de. Economia e política das finanças públicas: uma abordagem crítica da teórica convencional à luz da economia brasileira. Texto referência da disciplina Finanças Públicas, do Mestrado em Administração Pública da Fundação João Pinheiro, Belo Horizonte, 2001.

OLIVEIRA, Régis Fernandes de. Curso de direito financeiro. São Paulo: Revista dos Tribunais, 2006.

PAULANI, Leda. Alternativas para o Brasil no início do século XXI. In: SICSÚ, João (Org.). Arrecadação (de onde vem?) e gastos públicos (para onde vão?). São Paulo: Boitempo, 2007.

POCHMANN, Márcio. Gasto social, o nível de emprego e a desigualdade da renda do trabalho no Brasil. In: SICSÚ, João (Org.). Arrecadação (de onde vem?) e gastos públicos (para onde vão?). São Paulo: Boitempo, 2007.

SALVADOR, Evilásio. A distribuição da carga tributária: quem paga a conta? In: SICSÚ, João (Org.). Arrecadação (de onde vem?) e gastos públicos (para onde vão?). São Paulo: Boitempo, 2007. 